\title{
Corrigendum to "A Low-Cost Closed-Loop Solar Tracking System Based on the Sun Position Algorithm"
}

\author{
Muhammad E. H. Chowdhury, ${ }^{1}$ Amith Khandakar ${ }^{(D)}{ }^{1}$ \\ Belayat Hossain (D), ${ }^{2}$ and Rayaan Abouhasera ${ }^{1}$ \\ ${ }^{1}$ Electrical Engineering Department, College of Engineering, Qatar University, Doha 2713, Qatar \\ ${ }^{2}$ Department of EECS, Graduate School of Engineering, University of Hyogo, Kobe, Japan
}

Correspondence should be addressed to Amith Khandakar; amitk@qu.edu.qa

Received 22 April 2019; Accepted 12 May 2019; Published 9 June 2019

Copyright (C) 2019 Muhammad E. H. Chowdhury et al. This is an open access article distributed under the Creative Commons Attribution License, which permits unrestricted use, distribution, and reproduction in any medium, provided the original work is properly cited.

In the article titled "A Low-Cost Closed-Loop Solar Tracking System Based on the Sun Position Algorithm" [1], Dr. Belayat Hossain was incorrectly listed as the corresponding author. The corresponding author is Amith Khandakar.

\section{References}

[1] M. E. H. Chowdhury, A. Khandakar, B. Hossain, and R. Abouhasera, "A low-cost closed-loop solar tracking system based on the sun position algorithm," Journal of Sensors, vol. 2019, Article ID 3681031, 11 pages, 2019. 


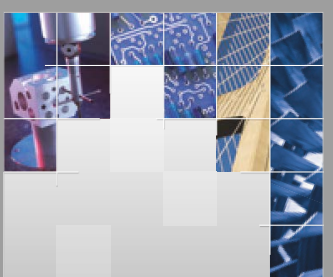

\section{Enfincering}
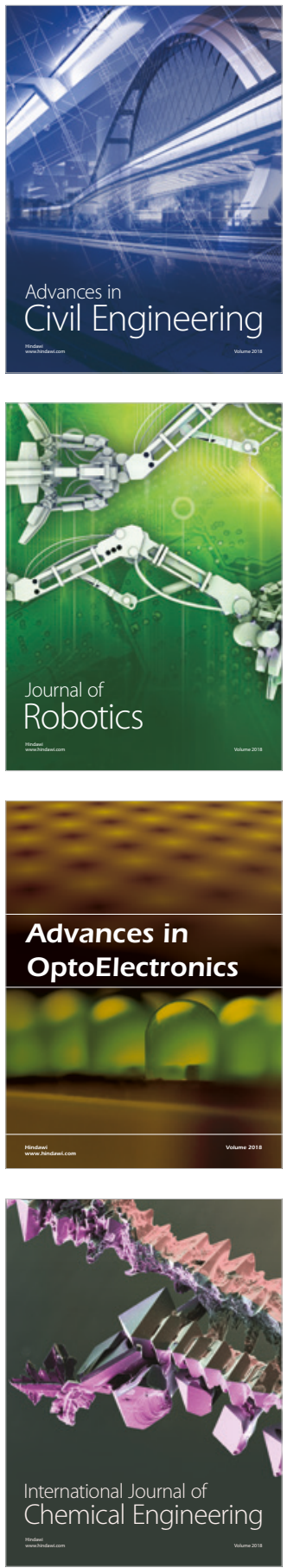

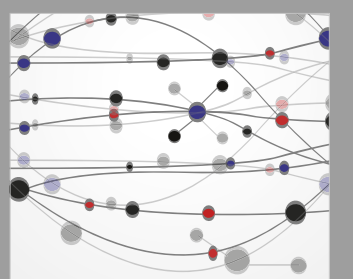

\section{Rotating \\ Machinery}

The Scientific World Journal

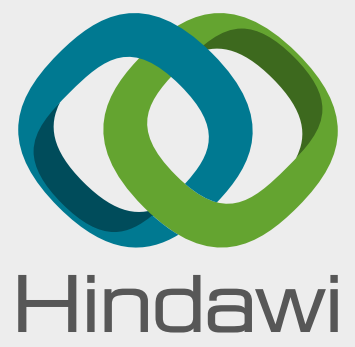

Submit your manuscripts at

www.hindawi.com
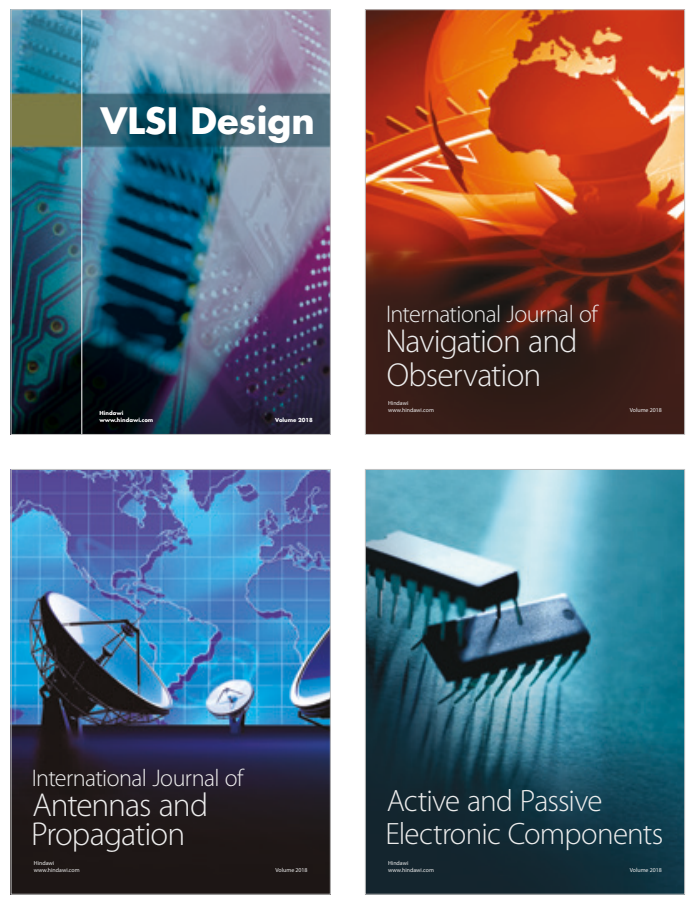
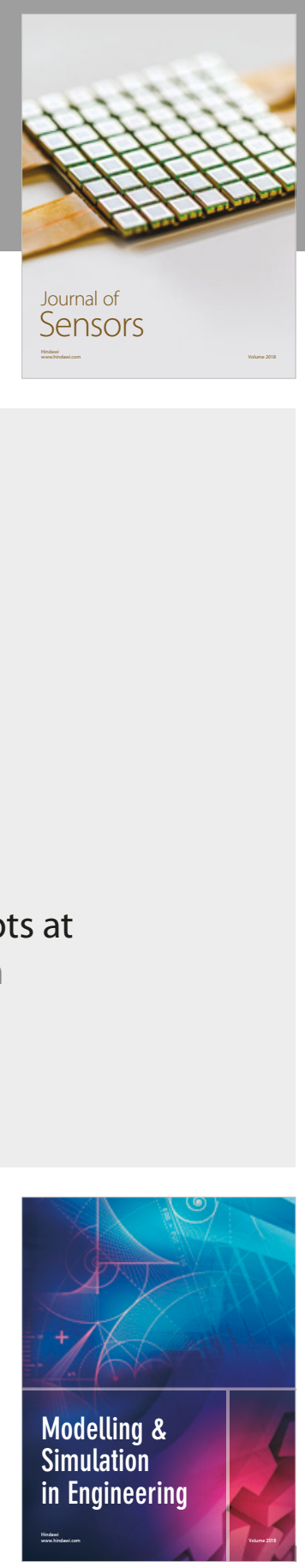

\section{Advances \\ Multimedia}
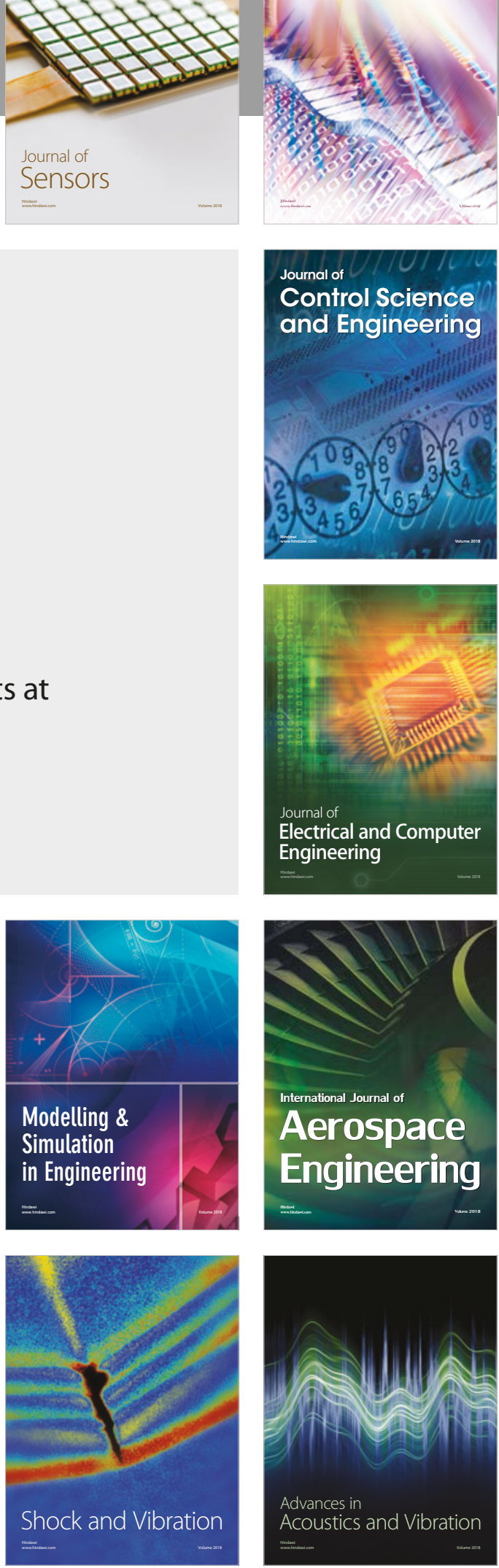